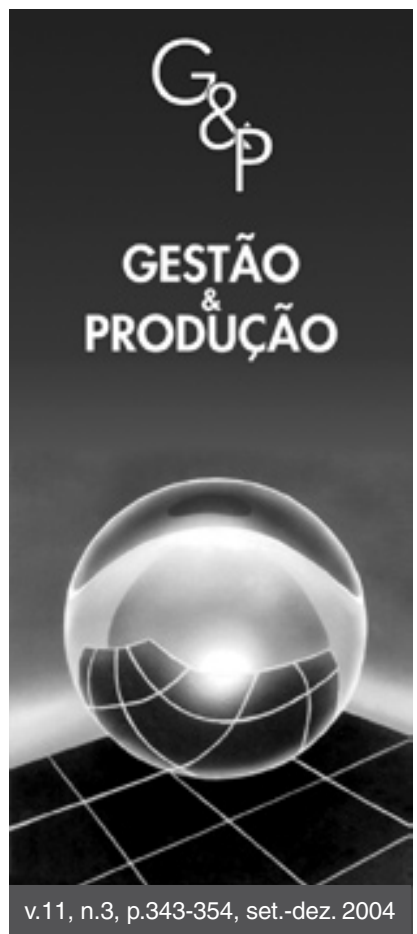

\title{
UMA ANÁLISE DAS CARACTERÍSTICAS DA ESTRUTURA DE GOVERNANÇA EM SISTEMAS LOCAIS DE PRODUÇÃO E SUAS RELAÇÕES COM A CADEIA GLOBAL
}

\author{
Renato Garcia \\ Flávia Gutierrez Motta \\ João Amato Neto
}

Departamento de Engenharia de Produção da Escola Politécnica, Universidade de São Paulo, Av. Almeida Prado, 128, CEP 05508-900, São Paulo, e-mail: renato.garcia@ poli.usp.br, fgmotta@yahoo.com, amato@usp.br

Resumo

Recebido em 22/3/2004

Aceito em 29/11/2004

Este trabalho tem o objetivo de analisar, de forma integrada, a problemática da governança global e local em sistemas locais de produção, com o intuito de verificar os condicionantes para a competitividade dos produtores e o desenvolvimento local. Para isso, são investigadas e comparadas duas experiências de sistemas locais de produção no Brasil: a indústria de calçados de Franca (SP) e a de móveis em Bento Gonçalves (RS). As principais evidências apontam que o desenvolvimento de capacitações entre os produtores localizados é condicionado pelas formas de governança, global e local, sobre a cadeia produtiva.

Palavras-chave: governança global, sistemas locais de produção, aglomerações industriais.

\section{Introdução}

Uma questão que vem recebendo atenção crescente, no debate sobre aglomerações de empresas, diz respeito às características das formas de coordenação da atividade produtiva. Em outras palavras, essa discussão se remete à governança do sistema local. Essa preocupação vem preencher uma lacuna importante das investigações concernentes às características dos sistemas locais, que normalmente têm sido direcionadas, quase que exclusivamente, aos seus elementos endógenos.

Poucos são os estudos que buscaram analisar a interação entre a governança local e suas relações com a cadeia global, ponto central da discussão deste trabalho. Nesse sentido, o objetivo do texto é analisar e apresentar os elementos básicos característicos dos sistemas locais de produção e discutir como os vínculos externos atuam e condicionam o desenvolvimento local. Para isso, é apresentada uma discussão dos principais conceitos envolvidos com esses argumentos para, em seguida, aplicá-los às experiências de aglomeração da indústria de calçados masculinos em Franca, no Estado de São Paulo, e de móveis de
Bento Gonçalves, no Estado do Rio Grande do Sul.

As aglomerações de empresas serão tratadas, neste estudo, como Sistemas Locais de Produção - SLPs, pois este é o termo que melhor descreve o fenômeno analisado, visto que o trabalho descreve locais onde operam vários subsistemas (produção, logística, distribuição, centros tecnológicos, etc.) que se entrelaçam por fatores sociais, econômicos, institucionais e geográficos, que dificilmente podem ser tratados de forma separada, e que possuem capacidades sistêmicas de aprendizado e inovação.

\section{Características gerais dos sistemas locais de produção}

Os sistemas locais de produção referem-se a agrupamentos de um conjunto de empresas concentradas geográfica e setorialmente. A aglomeração de produtores especializados gera uma estrutura em que se destacam as inter-relações no âmbito local, em virtude da presença de fornecedores de insumos e máquinas, prestadores de serviços e produtores de componentes. Em diversos casos, a aglomeração dos produtores é capaz de conformar 
uma estrutura produtiva completa, decorrente dos estímulos de mercado que são gerados para a instalação de negócios correlatos e de apoio. A literatura que aborda aglomerações tem mostrado que as empresas pertencentes a estes sistemas, tanto de países desenvolvidos como de países em desenvolvimento, são capazes de obter vantagens competitivas em relação às empresas dispersas geograficamente (Suzigan et al., 2001a; Lombardi, 2003). Assim, os produtores desses sistemas conseguem competir e melhorar seu desempenho no mercado doméstico e também superam restrições para atuarem em mercados distantes (Schmitz e Nadvi, 1999; Porter, 1998).

As vantagens competitivas das empresas em aglomerações industriais são de duas naturezas: as economias externas puras, de caráter incidental, e as ações conjuntas que são estabelecidas pelos agentes econômicos.

As economias externas à firma são decorrentes do extenso processo de divisão do trabalho verificado nos sistemas locais de produção e da especialização dos produtores, o que estimula a manutenção de interações mais freqüentes entre os agentes, e leva ao fomento de um processo local de aprendizado pela interação (learning-byinteracting). Tais benefícios são apropriados pelo conjunto dos produtores, mesmo que de forma assimétrica, de acordo com a capacidade de comando da cadeia local (e global) de produção.

Essas externalidades são o que Marshall (1985), em sua análise dos distritos industriais na Inglaterra no final do século XIX, chamou de retornos crescentes de escala, que são externos à firma, mas internos ao sistema local. Os retornos crescentes de escala emergem das condições de especialização dos agentes participantes do processo de divisão social do trabalho, proporcionando às unidades envolvidas ganhos de escala. Assim, a aglomeração de produtores especializados é capaz de atrair outras empresas que atuam na mesma indústria ou de setores correlatos e de apoio. Krugman (1998) chama a atenção para a existência de forças centrípetas, de caráter exclusivamente de mercado, que atraem novas atividades para o sistema local. E essa capacidade de atração de novas empresas acaba configurando uma estrutura produtiva, em que os agentes executam tarefas especializadas, intensificando o processo de divisão do trabalho entre os produtores. Nesse sentido, para Marshall (1985), as vantagens derivadas da concentração geográfica estão associadas com os ganhos de organização decorrentes da maior integração entre os agentes.

Além das economias externas, deve ser ressaltada a importância das ações conjuntas deliberadas (Schmitz, 1997). A concentração das empresas em aglomerações industriais é capaz de proporcionar um maior escopo para o estabelecimento de ações conjuntas deliberadas, que se transformam em importantes ganhos de competi- tividade para as empresas e são resultado de construções sociais especificas dos agentes locais. E, a partir do reconhecimento de que as economias externas não são puramente incidentais, mas construídas socialmente, Schmitz (1997) apresenta o conceito de eficiência coletiva, com o intuito de reunir as fontes das vantagens competitivas dos produtores aglomerados.

Scott (1998) enfatiza ainda que os atores locais têm papel fundamental na articulação com o poder público, na busca de auxílio para melhoria das condições competitivas dos produtores aglomerados: infra-estrutura e busca de soluções para problemas específicos. A forma de atuação do poder público é especifica às características da estrutura produtiva local e às rotinas e procedimentos dos agentes.

Em muitos casos a competitividade dos produtores em SLPs está baseada em fatores como o custo da mãode-obra ou o acesso privilegiado à matéria-prima, típicas vantagens competitivas de caráter estático. Todavia, esses fatores não são sustentáveis ao longo do tempo, já que tendem a ser anulados com o passar dos anos. Nesse sentido, as experiências brasileiras e internacionais bemsucedidas de SLPs mostram a capacidade dos produtores em sustentar suas vantagens competitivas em fatores dinâmicos, relacionados fundamentalmente com a inovação e a interação entre os agentes locais, incluindo também organismos de apoio, e o setor público (Belussi e Gotardi, 2000; Lombardi, 2003).

Portanto as análises sobre sistemas locais de produção enfocam, com maior ou menor grau, as duas principais vantagens que surgem da aglomeração: as economias externas e as formas de cooperação, privada (estabelecidas deliberadamente por empresas e instituições) ou por meio de políticas públicas específicas.

\section{Coordenação em sistemas locais de produção}

Nas análises sobre os sistemas locais de produção, poucos são os estudos que incorporam os efeitos dos vínculos não-locais que são estabelecidos pelos agentes. Porém parece fundamental analisar esse ponto, já que pode condicionar a forma de atuação das empresas locais. Nesse sentido, uma forma de análise desse fenômeno é pelo estudo do formato e da organização das cadeias produtivas globais, já que sistemas locais de produção são capazes de proporcionar vantagens não apenas às empresas aglomeradas, mas também a grandes compradores internacionais, que ali encontram produtores com elevada capacidade competitiva. A questão que se coloca nesse sentido é a capacidade de apropriação dessas vantagens competitivas pelos produtores locais.

Para isso, é preciso investigar a estrutura de coman- 
do (governança) que se verifica na cadeia produtiva, para identificar como os benefícios da concentração geográfica são apropriados entre os produtores locais e agentes exógenos ao sistema (como os grandes compradores globais).

Várias são as formas de comando local que podem ser estabelecidas para a coordenação das atividades produtivas entre firmas. Uma é o sistema centro-radial, que se configura quando há um claro comando de uma grande empresa local coordenadora das atividades de vários produtores de pequeno e médio porte. Neste caso, a empresa líder é quem se apropria da maior parte dos benefícios da cooperação (Markussen, 1995).

Há também a cooperação bilateral vertical, que se dá quando empresas inovadoras buscam, por meio da cooperação, diminuir os ciclos de inovação e assim conquistam vantagens competitivas preciosas para sua atuação no mercado. Já a cooperação horizontal bilateral ocorre quando empresas concorrentes se juntam para desenvolver um trabalho específico.

Verificam-se ainda formas de cooperação e iniciativas coletivas que envolvem diversos agentes e organismos públicos e privados. Entre elas podem ser verificadas as ações multilaterais horizontais, em que organismos públicos e/ou privados coordenam projetos setoriais, que envolvem a participação de várias empresas concorrentes, e as multilaterais verticais, em que cooperam instituições e empresas pertencentes a cadeias produtivas diferentes, a partir do estabelecimento de interações mais densas do que uma simples relação comercial.

Em todas as formas, fica claro o papel de formas de governança local para o incremento da competitividade dos produtores. As ações conjuntas deliberadas e as formas de governança que as sustentam exercem papel fundamental, para a inserção produtiva virtuosa dos produtores localizados. As formas de governança local, que levam à maior cooperação entre os produtores e ao incremento da competitividade do sistema, podem ser estabelecidas por entidades privadas ou públicas ou, ainda, pela combinação de ambas. Porém, muitas vezes, verificam-se formas híbridas de governança.

A existência de formas de governança nas interações entre os agentes locais não é capaz de eliminar as assimetrias de poder entre as empresas. Ao contrário, muitas vezes, reforça algumas dessas diferenças, e aqueles que detém ativos estratégicos da cadeia produtiva local se apropriam de mais vantagens que outros integrantes.

\section{Governança das cadeias produtivas globais}

O processo de desverticalização das grandes empresas ensejou o aparecimento de uma nova configuração da produção industrial. Tornou-se possível descentralizar operações detendo apenas as funções corporativas superiores, que proporcionam a apropriação de montantes mais expressivos do valor gerado nos processos de produção e comercialização das mercadorias. Além disso, a posse desses ativos-chave permite que as empresas exerçam o papel de coordenadoras (governadoras) da cadeia de suprimentos (Sturgeon, 2002; Furtado, 2003).

Para a análise dessas novas formas de organização da cadeia produtiva global, um aparato conceitual, bastante adequado, é a abordagem de Gereffi (1999) acerca das cadeias produtivas globais (ou Global Commodity Chains), que identifica a governança global da cadeia, ou seja, quem realiza a integração funcional e a coordenação de atividades internacionalmente dispersas, especificando e monitorando a performance dos produtores. Este referencial pode ser utilizado para caracterizar a estrutura global das cadeias produtivas de indústrias, como a de calçados e móveis. Com esse arcabouço, é possível compreender as possibilidades de desenvolvimento competitivo das empresas locais a partir dos eventuais fomentos ou restrições, que são colocados pelos detentores do comando das cadeias globais.

Os ativos-chave nestas cadeias são basicamente comerciais. A capacidade de comando está ligada ao fato da empresa deter o contato com o mercado consumidor, ou seja, deter marca forte e estabelecida ou canais próprios de comercialização e distribuição dos produtos. A essas capacitações, adicionam-se habilidades nas áreas de planejamento e desenvolvimento de produtos e design e no gerenciamento de uma rede de produtores geograficamente dispersa.

Vale observar que Lombardi (2003) apresenta uma solução distinta para o problema das interações entre os produtores locais e os mercados distantes. Para esse autor, a existência de concentração entre os produtores não elimina a necessidade de atores que fazem a ligação entre as capacitações do sistema local e a demanda - o que ele chama de final firms. Esses atores são responsáveis pela busca de informações sobre a demanda e as repassam aos produtores nos sistemas locais. Porém a transmissão das informações se dá de forma hierarquizada, já que são repassadas apenas informações parametrizadas de caráter tecnoprodutivo, o que lhes permite comandar o sistema local, além de beneficiar-se da concentração dos produtores.

De todo modo, verifica-se o papel fundamental exercido pelos agentes que fazem a ligação com a demanda. Os compradores, que normalmente são os detentores de marcas globais e de canais próprios de comercialização, acabam por exercer o poder de coordenação e comandam a apropriação de valor dos vários elos, determinando os produtos a serem fabricados, inclusive seu design, e to- 
das as especificações. Muitas vezes não possuem instalações fabris, mas fazem o marketing e a colocação destes produtos nos mercados, e adquirem a produção em estruturas produtivas globalmente dispersas. Porém, para que os grandes compradores estabeleçam este tipo de relação com as firmas, são necessários investimentos nas relações com as empresas e até fomento de um processo de aprendizado entre os produtores locais, nas áreas tecnoprodutivas. Nas estruturas produtivas, nas quais os grandes compradores adquirem, ou melhor, encomendam as mercadorias, eles estabelecem estruturas de apoio, no intuito de garantir que as condições acordadas e determinadas sejam cumpridas.

Esse é um dos motivos que faz com que os grandes compradores internacionais optem por adquirir as mercadorias em sistemas locais de produção, onde os custos de estabelecimento e manutenção dessas estruturas podem ser compartilhados entre um grande número de pequenas e médias empresas, fornecedoras de grandes lotes de produtos (Garcia, 2003).

Do lado dos produtores, a existência dessas estruturas de prestação de serviços é capaz de fomentar um processo de aprendizado local. A interação com os responsáveis pelo monitoramento da produção faz com que as empresas locais desenvolvam capacitações importantes nas suas funções produtivas, o que contribui para o incremento de sua capacidade competitiva. Gereffi (1999) afirma ainda que a interação produtores e compradores globais oferece formas para que os produtores locais alcancem processos de desenvolvimento de funções produtivas (upgrading), inclusive nas áreas de desenvolvimento de produto, design, marketing e marca, que são os ativos principais dos compradores. Entretanto, não é isso que vem demonstrando a experiência de SLPs no Brasil, já que são raros os casos de estruturas produtivas inseridas nas cadeias globais, nas quais os produtores foram capazes de desenvolver capacitações nas funções corporativas superiores. $\mathrm{O}$ desenvolvimento dos produtores fica restrito à esfera tecnoprodutiva, com ganhos expressivos em termos de produtividade e melhoria de processos e da qualidade dos produtos, mas com reduzidos efeitos dinâmicos em termos do desenvolvimento de produtos e, principalmente, da comercialização.

Assim, se os produtores brasileiros almejarem maior qualificação em funções comerciais, para se apropriarem de montantes mais expressivos do valor gerado pela cadeia, eles devem se organizar e buscar este objetivo de forma estruturada, intencional e aberta. Ou seja, deve ser uma meta a ser perseguida pelos agentes locais conscientemente, ou por meio do desenvolvimento de ações conjuntas, o que envolve a criação de centros de tecnologia, formação de associações de negócios, etc., ou pela ação de uma empresa líder que realize os investimentos, com- partilhe os custos e repasse os benefícios à sua rede de fornecedores. Desta forma, a geração de aprendizado e de melhorias em um SLP está diretamente associada à forma da governança local, que, por vezes, deve superar as barreiras impostas pela governança global que não tem interesse que os produtores localizados desenvolvam tais habilidades. Esta é a principal hipótese deste trabalho, e que é explorada por meio de dois estudos empíricos distintos, a indústria de calçados de Franca e a de móveis em Bento Gonçalves.

\section{Procedimentos metodológicos}

Para se alcançar os objetivos propostos, foram realizados estudos multi-casos em dois sistemas locais de produção, na indústria brasileira de duas cadeias produtivas distintas, a indústria de calçados de Franca, no Estado de São Paulo, e a indústria de móveis de Bento Gonçalves, no Estado do Rio Grande do Sul.

Os sistemas locais investigados atuam em setores diferentes, porém a configuração de poder de ambas as cadeias é parecida, já que o elo coordenador é dos compradores. Nesse sentido, o estudo realizado buscou compreender a forma de desenvolvimento da estrutura produtiva local, as estratégias utilizadas pelas empresas, o papel e o peso das instituições locais, as formas de interação com os compradores e os reflexos destas relações internas e externas sobre o desenvolvimento local. Estas questões foram exploradas não apenas junto à empresas produtoras, mas também a instituições de apoio aos produtores.

A pesquisa de campo foi realizada por meio de entrevistas com executivos das empresas, ou empresários, e com dirigentes das instituições de apoio, o que perfez um total consolidado de 65 entrevistas em empresas, sendo 30 em Franca e 35 em Bento Gonçalves. Procurouse abarcar empresas de diversos tamanhos e formas de atuação, de modo a elevar a representatividade da amostra. Além disso, foram visitadas todas as instituições de apoio aos produtores que atuam em cada sistema local. Por meio dessas visitas, foi possível levantar um conjunto de dados e informações que são apresentadas e discutidas nas próximas seções e sustentam as principais conclusões deste trabalho.

Para investigar a hipótese levantada - e apresentada na seção anterior -, foram definidos três conjuntos de variáveis que foram objeto do levantamento empírico, apontadas a seguir:

1. Formas de inserção dos produtores no mercado (doméstico e internacional): mercados em que atuam, forma de comercialização, meios de prospecção de mercado, comercialização;

2. Interação entre o mercado e o sistema local: papel dos compradores/vendedores, tipo de informações que são 
repassadas aos produtores (demanda, desenvolvimento de produto, tecnoprodutivas); e

3. Interação e aprendizado entre os produtores locais: formas de interação, fluxos de informações e conhecimento, interações usuário-produtor, papel dos centros de apoio e prestação de serviços.

A aplicação dessas variáveis nos casos selecionados, que é apresentada nas próximas seções, permitiu verificar a forma de governança local e o papel das interações com o mercado doméstico na impressão de maior dinamismo entre os produtores locais.

\section{A Indústria de calçados de Franca}

A estrutura produtiva da indústria de calçados brasileira, em convergência com as experiências internacionais mais importantes, caracteriza-se pela conformação de sistemas produtivos locais como forma de organização da produção. No caso brasileiro, diversas dessas aglomerações podem ser encontradas, mas duas delas se destacam: a região do Vale dos Sinos, no Estado do Rio Grande do Sul, que concentra um vasto conjunto diversificado de produtores e com certa especialização na fabricação de calçados femininos; e a região de Franca, no interior do Estado de São Paulo, que possui dimensões mais modestas e concentra produtores de calçados masculinos de couro.

Em ambas experiências, verifica-se uma estrutura produtiva na indústria de calçados bastante completa, que conta com a presença de diversos segmentos ligados à cadeia coureiro - calçadista, assim como de indústrias correlatas e de apoio, como fornecedores de máquinas, equipamentos e componentes para calçados - como fabricação de adesivos e selantes, de artefatos de borracha e de acessórios para calçados.

No caso específico de Franca, estimativas da associação local dos produtores indicam a existência de cerca de 400 empresas produtoras de calçados (dados do Sindifranca). Dados da RAIS/MTE de 2001 mostram, todavia, que havia um total de 23.500 pessoas formalmente empregadas em 1.458 estabelecimentos em toda a cadeia couro/calçados, o que representa algo em torno de $7 \%$ do emprego total no Brasil e cerca de $10 \%$ da produção doméstica. Desse contingente total de trabalhadores, 16.500 estavam empregados na atividade de fabricação de calçados de couro, o que comprova a forte especialização local. Além disso, o reduzido tamanho médio das firmas locais denotam a presença expressiva de empresas de pequeno e médio porte na estrutura produtiva local (Suzigan et al., 2001b).

Com o intuito de investigar as formas de governança existentes no sistema local e o papel das interações glo- bais para a conformação do esquema de coordenação da cadeia local, será aplicado aquele conjunto de variáveis definido na seção anterior.

Em primeiro lugar, serão investigadas as interações endógenas ao sistema local. Como é amplamente apontado na literatura, a aglomeração dos agentes é capaz de proporcionar diversos benefícios aos produtores, dadas as externalidades, incidentais ou deliberadas, que da aglomeração são geradas.

No caso de Franca, a pesquisa de campo mostrou claramente a importância das economias externas de caráter incidental, como a presença de trabalhadores qualificados e com habilidades específicas ao sistema local. As empresas têm custos muito reduzidos de recrutamento, seleção e treinamento de pessoal, já que há um amplo contingente de trabalhadores qualificados. Outro ponto notado diz respeito à presença de empresas fornecedoras de máquinas, equipamentos e de componentes para a fabricação de calçados, como já foi apontado. A concentração geográfica e setorial de produtores foi capaz de atrair indústrias correlatas e de apoio, que também são beneficiadas pela proximidade com seus usuários. Isso representa uma vantagem competitiva importante para os produtores locais, pois permite que as empresas tenham acesso mais facilitado e custos mais reduzidos a insumos e serviços do que se estivessem fora do sistema local. Por fim, também podem ser verificados expressivos e freqüentes transbordamentos (spill-overs) tecnológicos e de conhecimento, que se manifestam pela facilidade e pela velocidade de circulação das informações entre os agentes locais.

Porém, a despeito da importância das economias externas incidentais, os produtores de Franca pouco se aproveitam do elevado escopo para o estabelecimento de ações conjuntas, já que são verificadas poucas ações coletivas deliberadas, que teriam o efeito de elevar ainda mais a capacidade competitiva das empresas.

Em grande parte, isso se deve à estrutura de governança do sistema local, que é marcado por elevadas assimetrias e, por esse motivo, impede a realização de tarefas conjuntas mais duradouras entre os agentes. A primeira dessas assimetrias se refere à forma de organização da estrutura produtiva do sistema local, que denota a presença de empresas de tamanhos distintos e de variado poder de mercado. Existem algumas grandes empresas que atuam no mercado doméstico com marcas próprias e possuem elevado poder de barganha com compradores e com o restante da cadeia produtiva, e um vasto contingente de pequenas, médias e micro empresas, que em geral vendem produtos padronizados e auferem taxas de rentabilidade bastante reduzidas. Juntam-se a esses agentes um grande número de prestadores de serviços, as chamadas "bancas" de pesponto, que atuam no mercado informal 
como subcontratados das empresas de calçados.

Essa estrutura produtiva heterogênea e complexa gera elevadas assimetrias, que resultam em uma desigual capacidade de apropriação dos benefícios que são gerados pela aglomeração dos produtores. Grande parte das pequenas e médias empresas locais é incapaz de apropriarse de parcelas mais significativas do valor gerado ao longo dos processos de produção e distribuição das mercadorias, mesmo quando atuam no mercado doméstico. Suas estratégias, muitas vezes, são sufocadas pela ação das grandes empresas locais e pelos seus fornecedores.

Essa característica da estrutura de governança do sistema local está associada basicamente à forma de relacionamento do sistema local com o mercado - outra das variáveis definidas na investigação da estrutura de governança. Apenas algumas das empresas locais são capazes de fazer a ligação entre os produtores locais e a demanda externa e, assim, são capazes de hierarquizar as informações que são transmitidas pelos produtores locais. Nesse sentido, essas firmas repassam aos produtores apenas informações parametrizadas de caráter tecnoprodutivo. As pequenas empresas, por seu turno, não conseguem ter acesso a informações de mercado, que são hierarquizadas pelos agentes coordenadores. Na verdade, essas informações acabam sendo capturadas pelas empresas menores, por causa da existência de efeitos de transbordamento muito poderosos. Porém, isso ocorre com uma defasagem temporal relevante, que garante as vantagens competitivas das grandes empresas.

Outra característica danosa da estrutura de governança para o dinamismo do sistema local é a dificuldade encontrada pelos agentes em estabelecer ações conjuntas entre si. Diversas iniciativas conjuntas de empresas de pequeno e médio porte foram rapidamente sufocadas pela ação das grandes empresas locais e pelos seus fornecedores. Uma iniciativa interessante foi a de um grupo de 30 pequenas empresas, que ficou localmente conhecido como G30, que tentou, há alguns anos, criar um consórcio para compra de insumos estratégicos, tais como solados e adesivos, em melhores condições de negociação. O elevado poder de barganha dos fornecedores locais de adesivos e solados fazia com que os pequenos produtores tivessem uma desvantagem competitiva nessa área, já que raramente conseguiam comprar tais insumos nas mesmas condições que seus concorrentes de grande porte. Entretanto, essa iniciativa coletiva das pequenas empresas teve curta duração, já que a grande empresa local fornecedora de adesivos desestruturou o consórcio por meio de uma estratégia simples: passou a procurar cada uma das pequenas empresas do $\mathrm{G} 30$ oferecendo preços mais baixos do que o negociado com o consórcio. Com isso, os pequenos produtores de calçados abandonaram o consórcio, inviabilizando-o rapidamente.
Casos como esse revelam a dificuldade que as pequenas e médias empresas encontram para estabelecer ações conjuntas, já que existem interesses contrários a tais ações entre agentes que participam do sistema local. A ação das grandes empresas, muitas vezes, impede o estabelecimento de iniciativas coletivas das empresas de pequeno e médio porte com objetivo de melhorar suas condições competitivas.

O principal motivo pelo qual as ações conjuntas não são continuadas pelas empresas locais é o de que as grandes empresas, que assumem o papel de coordenadores do sistema local, não têm interesse no estabelecimento de ações coletivas que beneficiem o sistema produtivo como um todo, especialmente quando os principais beneficiários dessas ações são as empresas de pequeno e médio porte. Esses produtores são, na verdade, seus concorrentes no mercado doméstico, já que disputam a mesma fatia da demanda interna. Além do mais, do ponto de vista das pequenas empresas, o fracasso de tentativas passadas de estabelecimento de ações conjuntas faz com que os produtores se tornem ainda mais resistentes a outras iniciativas, como foi diversas vezes apontado pelos empresários entrevistados.

Outro elemento importante, determinante da estrutura de coordenação do sistema local, é o modo da interação das empresas do sistema local com a demanda externa, o que significa observar a forma de inserção das empresas locais no mercado internacional. Vale observar que a cadeia global de indústrias, como a de calçados, é bastante semelhante ao esquema apresentado por Gereffi (1999) de uma cadeia comandada pelo comprador, cujo papel é assumido pelas grandes lojas de varejo estadunidenses e européias, que possuem acesso aos grandes mercados mundiais e, por isso, são capazes de comandar a cadeia de produção e distribuição das mercadorias.

Os produtores brasileiros de calçados vêm participando dessas cadeias internacionais desde o início da década de 70, quando as empresas assumiram o papel de fornecedores de sapatos masculinos (a partir de Franca) e femininos de couro (a partir da região do Vale dos Sinos) a esses grandes compradores. Isso representou para a indústria brasileira de calçados como um todo, e para a de Franca em particular, um forte dinamismo, inclusive com avanços significativos na esfera da produção. A interação com os grandes compradores mundiais, na verdade com os escritórios de comércio (agentes exportadores) que foram montados no Brasil, proporcionou melhorias importantes em termos de tecnologia de processo, qualidade dos produtos e prazos de entrega.

Essas são tipicamente as informações parametrizadas e de caráter tecnoprodutivo, que os agentes coordenadores transmitem aos produtores locais. As informações de caráter mais estratégico, ligados ao comportamento da 
demanda e às tendências do mercado, ficam restritas aos agentes globais. Uma prova clara disso é que, em contraste com os avanços na esfera produtiva, as empresas de Franca inseridas nas cadeias internacionais apresentaram progressos pouco significativos nas esferas da comercialização e do desenvolvimento de produto e design, áreas que justamente são as maiores geradoras de valor na cadeia de produção e distribuição de calçados. A presença dos agentes exportadores, representantes dos grandes compradores mundiais, inibiu (ou impediu) avanços mais substantivos nessas áreas.

No que se refere à comercialização, os produtores apenas fornecem o calçado ao agente exportador, que se ocupa de todo o processo de distribuição dos produtos. Raramente a mercadoria é vendida com a marca do fabricante, e até a inscrição "Made in Brazil" aparece em local pouco visível. Já em termos de desenvolvimento de produto e design, os produtores praticamente não mantêm essa atividade internamente, já que a concepção, o modelo e, muitas vezes, o próprio preço do calçado a ser produzido são definidos pelo comprador, que repassa as informações aos produtores. Assim, os departamentos de desenvolvimento de produto das grandes empresas exportadoras de Franca se resumem, na maioria das vezes, a alguns poucos profissionais "modelistas", que apenas adaptam os modelos encomendados pelos grandes compradores ao processo produtivo, conferindo-lhes manufaturabilidade.

O resultado disso é que as empresas produtoras de calçados de Franca se sujeitam aos interesses dos grandes compradores internacionais, que determinam todos os atributos do produto, inclusive o seu preço. As empresas locais se tornam assim incapazes de vender seu próprio produto, já que têm de atender todas as especificações do comprador. Isso decorre da forma de inserção da indústria calçadista local na cadeia produtiva global do setor, em que os produtores brasileiros se encontram em uma posição de completa subordinação aos comandantes da cadeia produtiva, os grandes compradores internacionais e as empresas de comércio (trading companies) que os representam.

Esse ponto fica claro na análise comparativa entre empresas que atuam no mercado externo e aquelas que atuam no mercado doméstico. Como foi verificado na pesquisa de campo, há uma clara associação entre o destino da produção, mercado doméstico vs. internacional, e as atividades de desenvolvimento de produto e design: as empresas que destinam seus produtos, predominantemente, ao mercado doméstico possuem atividades de desenvolvimento muito mais densas do que aquelas que vendem no mercado internacional. Isso revela que, em contraste com os avanços na esfera produtiva, as empresas de Franca inseridas nas cadeias internacionais apre- sentaram progressos pouco significativos nas esferas do desenvolvimento de produto e design, e também na comercialização, tarefas que são realizadas pelos compradores. A presença dos agentes exportadores, representantes dos grandes compradores mundiais, inibiu avanços mais substantivos nessas áreas.

Portanto, nota-se que a aglomeração dos produtores de calçados na cidade de Franca, e de indústrias correlatas e de apoio, tem papel importante na geração de vantagens competitivas aos produtores locais. Todavia, existe um claro espaço para uma maior interação entre os agentes, o que possibilitaria a extração de benefícios ainda maiores para o conjunto dos produtores locais.

\section{A Indústria de móveis de Bento Gon- çalves}

A produção de móveis no Brasil está concentrada nas regiões Sul e Sudeste e é voltada basicamente para o mercado doméstico. Dentre as principais regiões produtoras, que se organizam na forma de sistemas locais de produção, duas aglomerações de empresas destacam-se pelo volume de produção e pela participação nas vendas externas: São Bento do Sul, no Estado de Santa Catarina, e Bento Gonçalves, no Estado do Rio Grande do Sul. Este estudo analisou o SLP de Bento Gonçalves, especializado na produção de móveis retilíneos fabricados com painéis de madeira reconstituída, e que destina em torno de $30 \%$ da produção para o mercado externo e $70 \%$ para o mercado interno (Sindmóveis, 2003).

No SLP de Bento Gonçalves, assim como em São Bento do Sul, há diversas empresas produtoras de móveis e também empresas de outros segmentos industriais, que se ligam à cadeia moveleira por meio do fornecimento de componentes, acessórios, partes, equipamentos e prestação de serviços. Portanto, são estruturas produtivas expressivas e integradas, capazes de conferir vantagens competitivas para os produtores locais.

Bento Gonçalves é uma região que vem se dedicando à produção de móveis desde o século XIX, a partir da colonização italiana. Porém, o grande impulso foi dado a partir da década de 70, quando o sistema local estruturou-se e ganhou forte dinamismo, o que permitiu aos produtores alcançarem níveis tecnológicos e de competitividade bastante elevados (Coutinho, 2000). Em 2001, a cidade de Bento Gonçalves respondia por aproximadamente $9 \%$ da produção brasileira de móveis e perto de $6 \%$ das exportações totais (Sindmoveis, 2003).

Com o intuito de comparar os casos de Bento Gonçalves e Franca, no sentido de analisar o impacto e os reflexos das formas de governança local, a configuração da estrutura produtiva local e a capacidade competitiva das empresas, foram analisadas a partir das variáveis iden- 
tificadas e descritas anteriormente (nos procedimentos metodológicos).

Deste modo, é possível notar que, ao contrário do sistema local de calçados de Franca, no SLP de Bento Gonçalves verificam-se não apenas as economias externas de caráter incidental, já que algumas ações conjuntas importantes têm sido estabelecidas pelos agentes locais, o que contribui para o incremento de competitividade dos produtores. Estas ações foram governadas pelas entidades locais de apoio aos produtores, que as articulam com as empresas e as diferentes esferas do poder público, além de outras instituições de fomento do país.

Primeiramente serão analisadas as interações entre as empresas locais. Como já foi previamente descrito, o SLP é formado por empresas de distintas indústrias relacionadas com o setor moveleiro, o que proporciona o surgimento de diversas economias externas de caráter incidental. A pesquisa de campo mostrou que todas as empresas admitem a importância da localização pela proximidade com fornecedores, a disponibilidade de mão-de-obra qualificada, e ficou evidente a ocorrência freqüente de spill-overs tecnológicos e de conhecimento. Vale ressaltar aqui que cinco empresas analisadas na amostra nasceram de desdobramentos dos negócios de grandes empresas do local. As empresas nascentes são, invariavelmente, resultados de especialização, visando suprir necessidades de fornecimento de materiais, equipamentos e serviços específicos.

Nos últimos cinco anos, além das vantagens inerentes à aglomeração, as associações locais têm articulado e viabilizado projetos de ações conjuntas entre empresas e instituições. Isto é resultado, por um lado, da indução de alguns programas e projetos federais e estaduais de apoio às atividades produtivas que tinham como foco a cooperação e, por outro, pela atuação do gerente executivo das entidades, que vêm concretizando a articulação local para a implementação dos projetos. Uma das razões do sucesso da implementação dessas ações é a configuração da estrutura produtiva local e a forma de governança.

Assim como no caso de Franca, a estrutura produtiva do sistema local de Bento Gonçalves é caracterizada pela heterogeneidade entre os agentes. No entanto, é possível observar algumas diferenças importantes nas formas de ação dos agentes locais.

A estrutura produtiva do sistema local de Bento Gonçalves é caracterizada por algumas empresas de grande e médio porte. Essas empresas normalmente atuam no mercado consumidor com marcas próprias e pontos exclusivos de comercialização. Em termos de processo produtivo, essas empresas realizam todas as fases internamente, e as compras de partes e de serviços de terceiros raramente atingem valores expressivos em relação aos custos de produção, o que as torna muito pouco dependentes dos fornecedores locais.
Em conjunto com essas empresas maiores, convivem diversas pequenas e médias empresas que produzem produtos padrão e de baixo valor agregado - e com margens de rentabilidade igualmente reduzidas. A forma de comercialização utilizada é normalmente o varejo convencional. Verifica-se ainda um contingente razoável de microempresas que atuam como fornecedores de componentes para as empresas não verticalizadas.

Essa estrutura produtiva heterogênea faz emergir, no sistema local, empresas com capacidade de comando das interações, que ocorrem entre os produtores. Porém, diferentemente do que ocorre em Franca, a pesquisa de campo em Bento Gonçalves identificou algumas ações conjuntas importantes, coordenadas pelas entidades de apoio aos produtores locais.

A maioria das ações trouxe benefícios para o sistema como um todo, como a implementação do curso de Tecnologia em Produção Moveleira na Universidade local (UCS/FERVI), que tem como objetivo principal formar recursos humanos em nível superior para a indústria. A parceria entre a Universidade e empresas possibilitou melhores condições para a adequação entre a demanda da indústria, por força de trabalho, e a montagem da estrutura do curso de formação, inclusive a sua grade curricular.

Há também um histórico recente de ações de cooperação multilateral. Dois projetos específicos merecem destaque.

O primeiro deles é o chamado "Centro Gestor da Inovação" (CGI), que tem o intuito de incrementar a competitividade dos produtores de Bento Gonçalves nas áreas de design e de serviços tecnológicos, por meio da prestação de serviços diferenciados e da capacitação dos produtores. Este projeto foi desenvolvido pela SEDAI (Secretaria de Desenvolvimento e dos Assuntos Internacionais do Estado do RS) juntamente com as entidades Sindmóveis, Movergs (Associações de Classe), Senai/ CETEMO (Centro Tecnológico), UCS (Universidade). Alguns resultados já foram produzidos, mas o ritmo de atividade ainda revela-se pouco dinâmico.

O segundo projeto a ser destacado é o "Desenvolvimento de Fornecedores e Redes de Empresas da Cadeia Produtiva de Madeira e Móveis", com o intuito de atuar na capacitação de micro e pequenas empresas, especialmente em áreas ligadas ao gerenciamento da produção. Este projeto foi desenvolvido pelo SEBRAE-RS, Sindmóveis, Movergs e MDIC (Ministério do Desenvolvimento da Indústria e do Comércio Exterior) hoje o projeto se desdobrou e 18 empresas estão estruturando uma Associação dos Fornecedores da Cadeia Moveleira com o objetivo de incentivar a troca de experiências, a realização de compras e o desenvolvimento de canais de comercialização compartilhados, com o objetivo básico de redução de custos operacionais. 
Além dessas ações, destaca-se ainda o SEBRAEXPORT, um consórcio de exportação que atende a diversas empresas de todo o Estado do Rio Grande do Sul, sendo parte delas da região de Bento Gonçalves, e a AFECOM (Associação dos Fabricantes de Estofados e Móveis Complementares), cujo intuito era a coordenação de iniciativas coletivas voltadas aos produtores locais desses segmentos.

Depreende-se assim o papel importante das instituições de apoio aos produtores, com destaque para as iniciativas de coordenação de ações conjuntas, voltadas ao incremento da competitividade das empresas. É interessante notar que essas ações acabam sucedendo-se umas às outras, muitas vezes, complementando seus objetivos e sua abrangência. Também se destaca a atuação conjunta e integrada das próprias entidades, voltadas para a promoção de maior integração da cadeia, contribuindo para o incremento da especialização dos produtores locais e para a intensificação das economias externas locais. A existência de tais ações conjuntas é decorrente, portanto, da coordenação exercida pelas entidades locais.

Outro fator revelado pela investigação empírica é que as empresas maiores do sistema também têm se beneficiado das ações conjuntas implementadas. Por exemplo, o SEBRAEXPORT conta com a participação de todas as grandes empresas locais e, dentre as empresas visitadas, elas declararam que alcançaram algum tipo de resultado por meio da participação no projeto, como aumento dos contatos, expansão das vendas externas, compreensão da forma de funcionamento de determinados mercados, entre outros. Além disso, não foi identificado algum tipo de restrição decisiva às iniciativas dessa natureza. Portanto as ações implementadas no local são governadas pelas instituições locais, que conseguem a adesão de diversas empresas de vários perfis, e cujos projetos têm gerado resultados e dinamismo entre os agentes. Aliás, vale ressaltar que o sucesso dos programas normalmente enseja novas iniciativas, que vão abarcando um número cada vez maior de produtores, o que revela o seu efeito essencialmente dinâmico, voltado ao fomento de um processo de aprendizado local e à construção de novas competências.

No que se refere à inserção dos produtores no mercado, observa-se a pequena participação das exportações nas vendas totais das empresas. Isso faz com que os produtores pouco se utilizem das operações dos compradores globais, na tarefa de repassar ao mercado os produtos locais. A atuação das empresas no mercado, nesse sentido, vincula-se com o desenvolvimento de canais próprios de comercialização e distribuição do produto, o que denota que a configuração da estrutura produtiva local e sua reduzida inserção na cadeia global têm efeitos positivos para o dinamismo do sistema.

De todo modo, percebe-se que tanto a hierarquização da circulação de informações, como o papel assumido pelos diferentes agentes, possui um caráter distinto na estrutura de governança do sistema local de Bento Gonçalves - em comparação com o de Franca. A compreensão desse fenômeno é bastante importante, pois acarreta diferenças importantes na forma de inserção dos produtores na cadeia de suprimentos e na sua capacidade de apropriação de valor ao longo do processo. Para tanto, foram identificados as formas de ação das empresas no mercado interno e externo, os mercados que são alcançados pelas empresas e os canais utilizados para comercialização.

Em termos da capacidade de apropriação do valor, a maior parte das empresas captura apenas uma pequena parte do valor gerado pela cadeia produtiva, por conta de duas razões principais. De um lado, as empresas produtoras não foram capazes de estabelecer ligações mais próximas com a demanda final, visto que os agentes coordenadores da cadeia, ou seja os compradores, é que desempenham este papel. Isto significa que as empresas moveleiras recebem instruções tecnoprodutivas prontas do que produzir, e desenvolvem suas habilidades quase que exclusivamente em áreas técnicas relacionadas com o processo de manufatura. Assim, as empresas não conseguem ter uma visão clara sobre aceitação dos produtos por parte do mercado, o comportamento dos consumidores e as tendências de mercado. Estas informações chegam de segunda-mão para os produtores, ou via varejo ou pelos efeitos de transbordamento de informações das empresas maiores, que têm este canal aberto. Nota-se que, em ambos os casos, os caminhos são indiretos. Esta dependência do varejo leva as empresas a terem seus ganhos achatados, pois, de um lado, recebem pressão dos custos da matéria-prima dos grandes fornecedores de painéis e, por outro, há pressão por preços do varejo. Portanto é uma participação subordinada e que depende das estratégias definidas pelo elo coordenador da cadeia.

Já as empresas que atuam com marcas próprias e possuem parcerias de exclusividade com os pontos de comercialização, conseguem acesso direto ao mercado final, abrindo assim um canal de comunicação com o consumidor. Estas empresas conseguem desenvolver seus negócios em consonância com as exigências do mercado e respondem rapidamente às mudanças de demanda. Normalmente, para atuar neste mercado, as empresas desenvolveram os móveis modulares/componíveis, o que significa o abandono quase que completo de linhas mais padronizadas. A diferença é que o demandante, a partir de sua disponibilidade de espaço e preferência de acabamento, faz um projeto customizado de acordo com suas necessidades, muito embora esses projetos não sejam personalizados e exista um limite na criação destes ambientes, dadas as diversas e variadas opções disponibi- 
lizadas pela empresa produtora. Este mercado foi desenvolvido pelas empresas que produziam móveis seriados, mas que queriam atingir o consumidor final, que antes recorria a pequenos marceneiros para desenvolver projetos personalizados.

Com esta forma de atuação, a indústria conseguiu atender a um segmento de mercado com maior poder aquisitivo, além de agregar uma gama de serviços aos produtos, o que aumentou as possibilidades de ganhos no mercado, ao mesmo tempo que proporcionou redução de custo para os projetos desenvolvidos para os consumidores - visto que produzem em escala, aplicando tecnologia avançada. As empresas que atuam desta forma são as mais rentáveis do setor, aplicam recursos substanciais no desenvolvimento de produtos e de habilidades comerciais e não competem com as empresas produtoras menores que atendem nicho de baixo valor agregado, portanto um perfil de consumidor diferente.

Assim, as grandes empresas não são afetadas com o desenvolvimento do negócio das pequenas empresas, que, por seu turno, atuam com linhas de produtos mais padronizados. As ações conjuntas estabelecidas e governadas pelas entidades, para aumentar a competitividade destas últimas, não representam ameaça ao negócio das empresas maiores.

Outra distinção importante é a ligação com o mercado externo, mesmo que isso ainda represente parcela pouco significativa das vendas totais. A comercialização se dá de duas formas mais importantes: as que são "compradas", que atuam de modo absolutamente passivo na inserção no mercado; e aquelas que buscam diretamente o mercado, procurando estabelecer seus próprios canais de comercialização e distribuição.

As empresas que atuam com foco em exportação se aproximam da forma de atuação das empresas do SLP de Franca, pois elas não exportam, mas os produtos "são comprados" pelos agentes globais que detêm as funções corporativas superiores, portanto estas empresas se apropriam de pequena parte do valor gerado pela cadeia e, além disso, não conseguem ter espaço para buscar maiores competências comerciais.

Com relação à outra forma de atuação, ou seja, a busca do mercado externo diretamente, as empresas o fazem por meio de alguns canais principais. O mais tradicional é quando as empresas realizam prospecções em busca de clientes, mas como resultado estabelecem ligações indiretas com o mercado final. Isto ocorre quando o importador fica assume a relação com o consumidor final colocando sua marca nos móveis, e os produtos sendo encomendados com base nos desenvolvimentos dos importadores. Esta forma de relação acontece principalmente quando as empresas buscam mercado de produtos populares e de baixo valor agregado, que são comercializados por meio das grandes redes de varejo. Neste caso, a rentabilidade da operação vincula-se exclusivamente com o seu volume e a relação de subordinação ao comprador é muito expressiva.

Em outros casos, a ligação com o mercado se dá por meio de empresas de varejo menores, em que o produtor é capaz de operar com produtos que foram desenvolvidos internamente. Isso exige, no entanto o desenvolvimento de capacitação em áreas "não-produtivas", como em termos da concepção e do design do produto.

A última forma de ligação é por meio de representantes da empresa no mercado de destino. Nesse caso, os produtores conseguem maiores informações sobre o mercado e, portanto, desenvolvem produtos mais adequados aos clientes.

Além destas formas de ligação com o mercado externo, duas empresas de médio porte, visitadas ao longo da pesquisa e que têm como foco o mercado interno, estão abrindo lojas exclusivas no exterior. Estas lojas são abertas com a bandeira da empresa, ou com a marca da empresa associada à marca do parceiro. Estas experiências ocorrem basicamente na América Latina, buscam adotar a estratégia de ligação com o mercado final que foi adotada no mercado doméstico, e que confere apropriação de maior parte do valor agregado gerado pela cadeia. Porém é uma experiência ainda tímida e sem muita agressividade comercial.

Portanto, o que se verificou é que as ligações que visam elevado volume produtivo e nicho de baixo valor agregado, que se atinge por meio dos grandes compradores globais, são canais inibidores do desenvolvimento de habilidades que não estejam ligadas às atividades produtivas, já, quando as ligações ocorrem com pequeno varejo, há uma maior dependência do comprador em relação às habilidades de desenvolvimento de produto do moveleiro, porém o volume é menor, o que demanda maior esforço comercial da empresa, e maior é o risco do negócio.

Desta forma, analisando os vários canais utilizados pelas empresas, para se ligarem ao mercado interno e externo, verificou-se que, de forma geral, a atuação das empresas no mercado doméstico as levam a maiores possibilidades de desenvolvimento de competências em áreas como desenvolvimento de produtos, design e ativos comerciais do que as que se focam no mercado internacional. E, analisando as ligações desenvolvidas com o mercado externo, verificam-se diferentes formas de atuação: na forma tradicional, por meio das grandes redes de varejo ou grandes distribuidores/importadores, nos quais as possibilidades de se apropriar de maior valor agregado e de ter desenvolvimento em áreas estratégicas da cadeia é muito restrita; via representantes próprios ou pequenos varejos, em que as possibilidades de ganho se ampliam; ou via parcerias com pontos de comercialização no mer- 
cado de destino, mas, neste caso, os investimentos necessários, para desenvolver tais competências, e os riscos do negócio também aumentam substancialmente.

\section{Considerações finais e implicações normativas}

A análise dos sistemas locais de produção de Franca e de Bento Gonçalves pode trazer algumas lições importantes, para a compreensão das formas de configuração produtiva dos produtores localizados, dos esquemas de governança e da inserção dos produtores em cadeias globais de produção, comercialização e distribuição de mercadorias.

Em primeiro lugar, nota-se que em ambos os casos o padrão de comercialização dos produtos para o mercado doméstico é bastante parecida, já que em ambos os casos as empresas locais assumem as tarefas de desenvolvimento de produto e design e detêm canais próprios de distribuição e comercialização de suas mercadorias. Essa tarefa é assumida pelas grandes empresas locais, que muitas vezes exercem o papel de comando de uma ampla cadeia de suprimento dessas mercadorias. No SLP de Bento Gonçalves, essa característica torna-se mais evidente e importante, já que as empresas destinam sua produção quase que integralmente ao mercado doméstico.

Porém, no que se refere à inserção no mercado externo, a forma de atuação difere substancialmente, já que as empresas, especialmente as produtoras de calçados de Franca, são incapazes de assumir as tarefas de concepção, desenvolvimento e comercialização de seus produtos. Nesse caso, essas funções são assumidas pelos grandes compradores globais. O resultado disso é que as empresas são "compradas" pelos demandantes internacionais, já que são incapazes de exercer qualquer influência sobre os termos de negociação com os compradores. Na verdade, ocorre que os compradores globais exercem o papel de ligação dos produtores com a demanda externa e, por isso, são capazes de hierarquizar as informações que são transmitidas aos produtores, restrigindo-as aos elementos tecnoprodutivos envolvidos no processo.

O reconhecimento de que essa forma de inserção tem limites muito claramente delimitados tem implicações normativas muito significativas, já que, ao inserirem-se nos esquemas globais de produção, os produtores têm suas possibilidades de crescimento e de acumulação de capacitações fortemente limitadas às funções produtivas.

Esse problema é particularmente importante na análise do sistema local de produtores de calçados de Franca, em que o desenvolvimento das firmas esteve fortemente associado ao incremento da participação das empresas no mercado internacional. Isso fez com que os produtores desenvolvessem capacitações importantes na esfera produtiva, mas impediu que as firmas acumulassem novos conhecimentos em outras áreas do seu negócio. A experiência da indústria de calçado de Franca mostra que as firmas não estão muito dispostas a estabelecer ações conjuntas relevantes, o que os impede de se apropriar de uma das fontes das vantagens competitivas das aglomerações de empresas. Porém, essa forma de atuação possibilitou um rápido crescimento das empresas, dado pelo dinamismo das exportações de produtos "encomendados" pelos compradores. Nesse sentido, a escolha pela forma de crescimento rápido dos produtores locais trouxe consigo uma dificuldade de manutenção desse dinamismo a longo prazo, em virtude da baixa dependência do comprador em relação às competências desenvolvidas pelas empresas locais.

Já os produtores de Bento Gonçalves têm procurado aproveitar-se da proximidade geográfica e cultural entre si, para estabelecer alguns projetos conjuntos e com custos compartilhados, com o intuito principal de suprir algumas insuficiências do sistema local, que têm impedido uma inserção mais virtuosa dos produtores. Esta forma de desenvolvimento menos dependente dos agentes globais representa, por um lado, um ritmo de crescimento menos acelerado aos produtores locais, mas, por outro, pode representar uma forma de desenvolvimento mais sustentável, capaz de criar vantagens competitivas dinâmicas aos produtores, por meio da acumulação de competências e habilidades entre os produtores locais nas diversas áreas da operação da empresa. Exemplos disso são as ações voltadas às funções superiores, como aquelas no campo da tecnologia, do desenvolvimento de produto e design e a tentativa de estabelecer canais próprios e compartilhados de comercialização para o exterior.

Nesse sentido, no caso de Franca, há um campo para incremento das vantagens competitivas dos produtores locais, por meio do estabelecimento de ações conjuntas, voltadas à superação dos obstáculos criados por uma forma de inserção internacional pouco dinâmica. Isso poderia se dar por meio da ação de organismos locais de apoio aos produtores, mas é preciso romper com o atual e deteriorado sistema de governança local, que tem impedido o avanço dessas ações. Já no caso de Bento Gonçalves, as formas de governança global, e as eventuais dificuldades impostas pela relação com os compradores globais, ficam restritas às empresas exportadoras, com poucos efeitos multiplicadores dentro do sistema local, visto que estas empresas são verticalizadas e com pouca interação com outras empresas do local. Dessa forma, as diversas ações conjuntas que são estabelecidas pelos agentes acabam exercendo papel importante na construção de vantagens competitivas mais sustentáveis a longo prazo. 


\title{
Referências Bibliográficas
}

BELUSSI, F.; GOTTARDI, G. Evolutionary Patterns of Local Industrial Systems - towards a cognitive approach to the industrial district. Aldershot: Ashgate, 2000. $195 \mathrm{p}$.

COUTINHO, L. et al. Design como fator de competitividade na indústria moveleira. Curitiba: Alternativa, 2000. 103 p.

FURTADO, J. (Org.) Globalização das cadeias produtivas no Brasil. São Carlos: UFSCar, 2003. 245p.

GARCIA, R. (2003). Learning and upgrading in industrial clusters: the relation between local producers and global buyers. In: EUNIP, 7., 2003, Porto. Proceedings... Disponível em: <http://www.fep.up.pt/conferences/eunip2003>. Acesso em: 20 maio 2004.

GEREFFI, G. International trade and industrial upgrading in the apparel commodity chain. Journal of International Economics, v. 48, p. 31-70, jun. 1999.

GORINI, A. P. F. A indústria de móveis do Brasil. Curitiba: Alternativa, 2000. 80 p.

KRUGMAN, P. What's new about the New Economic Geography? Oxford review of economic policy, v. 14, n. 2, 1998.

LOMBARDI, M. The Evolution of Local Production Systems: the emergence of the "invisible mind" and the evolutionary pressures towards more visible "minds". Research Policy, v. 32, n. 9, set. 2003

MARKUSSEN, A. Áreas de atração de investimentos em um espaço econômico cambiante: uma tipologia de distritos industriais. Nova Economia. Belo Horizonte. v. 5, n. 2, p. 9-44, dez, 1995.
MARSHALL, A. Princípios de economia. 3. ed. São Paulo: Nova Cultural, $1985.730 \mathrm{p}$.

PORTER, M. Clusters and the economics and competition. Harvard Business Review, p. 77-90, nov-dez, 1998.

SCHMITZ, H. (1997). Collective efficiency and increasing returns. IDS Working Paper, Brighton, IDS, n. 50, march, 1997. Disponível em <http://www.ids.ac.uk/ids/ bookshop/wp/wp50.pdf> Acesso: 10 dezembro 2003.

SCHMITZ, H.; NADVI, K. Clustering and industrialization: introduction. World Development, v. 27, n. 9, set. 1999.

SCOTT, A. The geographic foundations of industrial performance. In: CHANDLER, A.; HAGSTRON, P.; SOLVELL, O. The dynamic firm: the role of technology, strategy, organization, and regions. Oxford University Press, 1998. 488 p.

SINDMÓVEIS. Dados do setor, 2003. Disponível em http:// www.sindmoveis.com.br. Acesso: 20 abril 2003.

STURGEON, T. Modular production network: a new American model of industrial organization. Industrial and Corporate Change, v. 3, n. 11, 2002.

SUZIGAN, W.; FURTADO, J.; GARCIA, R.; SAMPAIO, S. Aglomerações industriais no estado de São Paulo. Economia Aplicada, v. 5, n. 4, out-dez, 2001 a.

SUZIGAN, W.; FURTADO, J.; GARCIA, R.; SAMPAIO, S. Sistemas Locais de Produção no estado de São Paulo: o caso da indústria de calçados de Franca. In: TIRONI, L.F. (Coord.). Industrialização Descentralizada: sistemas industriais locais. Brasília: IPEA. 2001b. 533 p.

\section{AN ANALYSIS OF THE CHARACTERISTICS OF THE GOVERNANCE STRUCTURE IN LOCAL PRODUCTION SYSTEMS AND ITS RELATIONS WITH THE GLOBAL CHAIN}

\begin{abstract}
This paper analyzes industrial clusters, characterizing and integrating the view of global and local governance and identifying the conditioning factors of producer competitiveness and local development. To this end, the paper investigates two Brazilian industrial clusters: the footwear industry in Franca, SP and the furniture industry in Bento Gonçalves, RS. The main findings show that the forms of global governance of the production chain are crucial conditioning factors of the development of capabilities among local producers.
\end{abstract}

Keywords: global governance, local production systems, industrial clusters. 